\title{
Mastering Many by Counting, Re-counting and Double-counting before Adding On-top and Next-to
}

\author{
Allan Tarp \\ The MATHeCADEMY.net, Denmark
}

Observing the quantitative competence children bring to school, and by using difference-research searching for differences making a difference, we discover a different 'Many-matics'. Here digits are icons with as many sticks as they represent. Operations are icons also, used when bundle-counting produces two-dimensional block-numbers, ready to be re-counted in the same unit to remove or create overloads to make operations easier; or in a new unit, later called proportionality; or to and from tens rooting multiplication tables and solving equations. Here double-counting in two units creates per-numbers becoming fractions with like units; both being, not numbers, but operators needing numbers to become numbers. Addition here occurs both on-top rooting proportionality, and next-to rooting integral calculus by adding areas; and here trigonometry precedes geometry.

Keywords: numbers, operations, proportionality, calculus, early childhood

Being highly useful to the outside world, mathematics is a core part of institutionalized education. Consequently, research in mathematics education has grown as witnessed e.g. by the International Congress on Mathematics Education taking place each four year since 1969. However, despite 50 years of research, many countries still experience poor results in the Programme for International Student Assessment (PISA). In the former model country Sweden this caused the Organisation for Economic Co-operation and Development (OECD) to write the report 'Improving Schools in Sweden' describing its school system as 'in need of urgent change' since 'more than one out of four students not even achieving the baseline Level 2 in mathematics at which students begin to demonstrate competencies to actively participate in life.' (OECD, 2015, p. 3).

Mathematics thus seems to be hard by nature. But, with mathematics and education as social institutions, a different answer, by choice, may come from sociology, having imagination as a core part as pointed out by Mills (1959). Bauman (1990) agrees when talking about organizations:

Sociological thinking is, one may say, a power in its own right, an anti-fixating power. It renders flexible again the world hitherto oppressive in its apparent fixity; it shows it as a world which could be different from what it is now. 
(p.16) Rational action (..) is one in which the end to be achieved is clearly spelled out, and the actors concentrate their thoughts and efforts on selecting such means to the end as promise to be most effective and economical. (p.79) Last but not least, the ideal model of action subjected to rationality as the supreme criterion contains an inherent danger of another deviation from that purpose - the danger of so-called goal displacement. (..) The survival of the organization, however useless it may have become in the light of its original end, becomes the purpose in its own right: the new end against which the organization tends to measure the rationality of its performance (p.84).

It is a general opinion that the goal of mathematics education is to learn mathematics. However, this goal is self-referring. So maybe traditional mathematics has a goal displacement hiding a different more fruitful way to the outside goal, to master Many as it occurs in space and time?

\section{Difference-research}

To find differences we use 'Difference-research' (Tarp, 2018a) searching for differences making a difference, thus containing two parts: finding a difference, and testing it to see if it makes a difference. This paper focuses on the first part in order to find differences that can be tested to create a background for a possible paradigm shift (Kuhn, 1959).

Difference-research builds on sociological imagination; and on the skeptical thinking of the ancient Greek sophists warning against choice presented as nature. Thus disagreeing with Plato seeing choice as an illusion since the physical is but examples of meta-physical forms visible only to philosophers educated at his academy, later by Christianity turned into monasteries before being changed back again by the Reformation. In the Renaissance, this created the skeptical thinking of natural science, which rooted the Enlightenment century with its two republics, the American and the French (Russell, 1945).

Where France now has its fifth republic, the USA still has its first with skepticism as pragmatism and symbolic interactionism and grounded theory. To protect its republic, France has developed a skepticism inspired by the German thinker Heidegger, seen by Bauman as starting 'the second Copernican revolution' by asking: What is 'is'? (Bauman, 1992, p. ix).

Heidegger (1962) sees three of our seven basic is-statements as describing the core of Being: 'I am' and 'it is' and 'they are'; or, I exist in a world together with It and with They, with Things and with Others. To have real existence, the 'I' must create an authentic relationship to the 'It'. However, this is made difficult by the 'dictatorship' of the 'They', shutting the 'It' up in a predicate-prison of idle talk, gossip.

Heidegger thus uses existentialist thinking, described by Sartre (Marino, 2004) as holding that 'existence precedes essence' (p. 22). In France, Heidegger inspired the poststructuralist thinking pointing out that society 
forces words upon you to diagnose you so it can offer cures including one you cannot refuse, education, that forces words upon the things around you, thus forcing you into an unauthentic relationship to yourself and your world (Foucault, 1995; Lyotard, 1984; Tarp, 2016).

Difference-research tells what can be different from what cannot. From a Heidegger view, an is-sentence contains two things: a subject that exists and cannot be different, and a predicate that can and that may be gossip masked as essence, provoking 'the banality of Evil' (Arendt, 1963) if institutionalized. So, to discover its true nature, we need to meet the subject, Many, outside the predicate-prison of traditional mathematics. We will use Grounded Theory (Glaser and Strauss, 1967), lifting Piagetian knowledge acquisition (Piaget, 1970) from a personal to a social level, to allow Many create its own categories and properties. In this way, we can see if our observations can be assimilated to traditional mathematics or will suggest it be accommodated.

\section{Our Two Languages with Word- and Number-Sentences}

To communicate we have two languages, a word-language and a number-language. The word-language assigns words to things in sentences with a subject, a verb, and an object or predicate: 'This is a chair'. As does the number-language assigning numbers instead: 'the 3 chairs each have 4 legs', abbreviated to 'the total is 3 fours', or ' $T=34 \mathrm{~s}$ ' or ' $T=3 * 4$ '. Unfortunately, the tradition hides the similarity between word- and number-sentences by leaving out the subject and the verb by just saying ' $3 * 4=12$ '.

Both languages have a meta-language, a grammar, describing the language, describing the world. Thus, the sentence 'this is a chair' leads to a meta-sentence ' 'is' is an auxiliary verb'. Likewise, the sentence ' $T=3 * 4$ ' leads to a meta-sentence ' $*$ ' is a commutative operation'.

Since the meta-language speaks about the language, we should teach and learn the language before the meta-language. This is the case with the word-language only. Instead its self-referring set-based form has turned mathematics into a grammar labeling its outside roots as 'applications', used as means to dim the impeding consequences of teaching a grammar before its language.

So, using full sentences including the subject and the verb in number-language sentences is a difference to the tradition; as is teaching language before grammar.

\section{Mathematics, Rooted in Many, or in Itself}

The Pythagoreans used mathematics, meaning knowledge in Greek, as a common label for their four knowledge areas: arithmetic, geometry, music and astronomy (Freudenthal, 1973), seen by the Greeks as knowledge about Many by itself, Many in space, Many in time and Many in space and time. Together 
they formed the 'quadrivium' recommended by Plato as a general curriculum together with 'trivium' consisting of grammar, logic and rhetoric (Russell, 1945).

With astronomy and music as independent areas, today mathematics should be a common label for the two remaining activities, geometry and algebra, both rooted in the physical fact Many through their original meanings, 'to measure earth' in Greek and 'to reunite' in Arabic.

However, 50 years ago the set-concept created a self-referring 'New Math' or 'meta-matics' with concepts defined top-down as examples from abstractions instead of bottom-up as abstractions from examples. And neglecting that Russell, by looking at the set of sets not belonging to itself, showed that self-reference leads to the classical liar paradox 'this sentence is false' being false if true and true if false: If $M=\{A \mid A \notin A\}$ then $M \in M \Leftrightarrow$ $M \notin M$.

So, to find a difference we now return to the Greek origin to meet Many openly to uncover a 'Many-matics' as a natural science about Many.

\section{Meeting Many, Children use Block-numbers to Count and Share}

How to master Many can be observed from preschool children. Asked 'How old next time?', a 3year-old child will say 'Four' and show 4 fingers; but will react strongly if held together 2 by 2, 'That is not 4 , that is $22 \mathrm{~s}$.'

Children thus describes what exists in the world: bundles of $2 \mathrm{~s}$, and 2 of them. So, what children bring to school is 2-dimensional block-numbers, illustrated geometrically by LEGO blocks, together with some quantitative competence. Children thus love re-counting 5 sticks in $2 \mathrm{~s}$ in various ways as 1 2s \& 3, as 2 2s \& 1 , and as 32 s less 1 .

Sharing nine cakes, four children take one by turn saying 'I take 1 of each 4'. With 1 left they might say 'let's count it as 4'. Thus, children share by taking away 4 s from 9 , and by taking away 1 per 4, and by taking 1 of 4 parts.

Children quickly observe the difference between a 'stack-number' as 6 $=32 \mathrm{~s}$ or $23 \mathrm{~s}$, and a prime number as 3 , serving only as a bundle-number by always leaving singles if stacked.

Finally, by turning and splitting 2-dimensional or 3-dimensional blocks, children see their commutative, distributive and associative properties as self-evident: of course, $23 \mathrm{~s}$ is the same as $32 \mathrm{~s}$; and $63 \mathrm{~s}$ can be split in $43 \mathrm{~s}$ and $23 \mathrm{~s}$; and $23 * 4 \mathrm{~s}$ is the same as $2 * 34 \mathrm{~s}$.

\section{Meeting Many Openly}

Many exists in space and time as multiplicity and repetition. Meeting Many we ask: 'how many in total?' To answer, we count and add. We count by 
bundling and stacking as seen when writing out fully the total $T=456=4^{*} B^{\wedge} 2$ $+5^{*} B+6^{*} 1$ showing three stacks or blocks added next-to each other: one with 4 bundles of bundles, one with 5 bundles, and one with 6 unbundled singles. Typically, we use ten as the bundle-size, formally called a base.

Digits occur by uniting e.g. five ones to one fives, rearranged as an icon with five strokes if written less sloppy. As the bundle-size, ten needs no icon when counted as 10, one bundle and no unbundled. Then follow eleven and twelve coming from Danish Vikings counting 'one left' and 'two left'.

\begin{tabular}{|c|c|c|c|c|c|c|c|c|}
\hline 1 & 2 & 3 & 4 & 5 & 6 & 7 & 8 & 9 \\
\hline I & II & III & IIII & |IIII & IIIIII & IIIIIII & ||||||||| & |||||||||| \\
\hline & 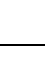 & & 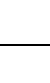 & $\square$ & $\square$ & $\square$ & $\square$ & $\square$ \\
\hline
\end{tabular}

Figure 1. Digits as icons with as many sticks as they represent.

\section{Counting by Bundling}

We count in several ways. Some gather-hunter cultures count 'one, two, many'. Agriculture needs to differentiate degrees of Many and typically bundles in tens. To include the bundle, we can count 'OBundle $1,0 B 2,0 B 3, \ldots$, $1 B, 1 B 1,1 B 2$ ', etc.; or ' 0.1 tens, 0.2 tens', etc., using a decimal point to separate the bundles from the unbundled singles. To signal nearness to the bundle we can count ' $1,2, \ldots, 7$, bundle less 2 , bundle less 1 , bundle', etc. Thus a number always contains three numbers: a number of bundles, a number of singles, and a number for the bundle-size.

Bundle-counting, we ask e.g. 'A total of 7 is how many 3s?' Using blocks, we stack the 3-bundles on-top of each other. The single can be placed next-to, or on-top counted in $3 \mathrm{~s}$. Thus, the result of counting 7 in $3 \mathrm{~s}, T=23 \mathrm{~s} \&$ 1, can be written as $T=2 B 13 \mathrm{~s}$ using 'bundle-writing', and as $T=2.13 \mathrm{~s}$ using 'decimal-writing', and as $T=21 / 33$ s using 'fraction-writing'.

Figure 2. Seven bundle-counted as 2Bundle1 $3 s$, as $2.13 s$, and as $21 / 33 s$.

\section{Bundle-counting in Space and Time}

We include space and time by using 'geometry-counting' in space, and 'algebra-counting' in time. Counting in space, we stack the bundles and report the result on an abacus in 'geometry-mode'. Here the total 7 is on the below bar with 1 unbundled and a block with 2 bundles on the bars above.

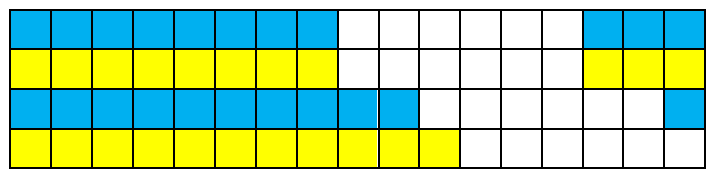


Figure 3. Seven bundle-counted as $2 B 13 s$ on an abacus in geometry-mode.

Counting in time, we count the bundles and report the result on an abacus in 'algebra-mode'. Here the total 7 is on the below bar with 1 unbundled and the number of bundles on the bars above.

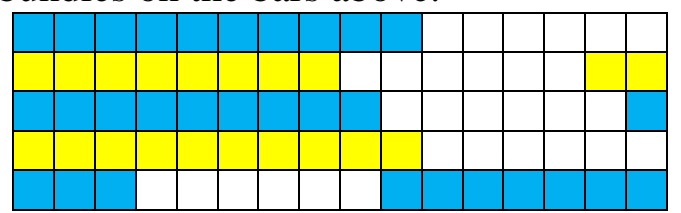

Figure 4. Seven bundle-counted as 2.13 s on an abacus in algebra-mode.

\section{A Calculator Predicts Counting-results}

Iconizing the counting processes also, a calculator can predict a counting-result. A stack of $23 \mathrm{~s}$ is iconized as $2 \times 3$ (or $2 * 3$ ) showing a lift used 2 times to stack the $3 \mathrm{~s}$. As for taking away, subtraction shows the trace left when taking away just once, and division shows the broom wiping away several times.

So, entering ' $7 / 3$ ' we ask the calculator 'from 7,3 s can be taken away how many times?' The answer is ' 2 . some'. To find the leftover singles we take away the stack of $23 \mathrm{~s}$ by asking ' $7-2 * 3$ '. From the answer ' 1 ' we conclude that $7=2 B 13 \mathrm{~s}$. Showing ' $7-2 * 3=1$ ', a display indirectly predicts that 7 can be re-counted as $23 \mathrm{~s}$ and 1 , or as $2 B 13 \mathrm{~s}$ or $2.13 \mathrm{~s}$.

\begin{tabular}{|lr|}
\hline $\mathbf{7} / \mathbf{3}$ & 2. some \\
$\mathbf{7}-\mathbf{2} * \mathbf{3}$ & 1 \\
\hline
\end{tabular}

Figure 5. A calculator predicts how 7 re-counts in $3 \mathrm{~s}$ as $2.13 \mathrm{~s}$.

A calculator thus uses a 're-count formula', $T=(T / B)^{*} B$, saying that 'from $T, T / B$ times, $B$ s can be taken away'; and a 're-stack formula', $T=(T-$ $B)+B$, saying that 'from $T, T-B$ is left, if $B$ is taken away and placed next-to'. The formulas may be illustrated by LEGO blocks. The re-count formula introduces early algebra (Kieran, Pang, Schifter and $\mathrm{Ng}, 2016$ ) from grade one; and it occurs all over mathematics and science as proportionality formulas. Likewise, the early use of a calculator shows the importance of mathematics as a language for prediction.

\section{Cup-Counting Allows Re-Counting in the Same Unit}

Cup-counting uses a cup when bundle-counting e.g. 7 in 3 s. For each bundle we place a stick inside the cup, leaving the unbundled singles outside.

$\mathrm{T}=7=\mathrm{I} \mathrm{I} \mathrm{II} \mathrm{II} \rightarrow \mathrm{HHH} \rightarrow[\mathrm{ID} \mathrm{I} \rightarrow 2 \mathrm{~B} 13 \mathrm{~s}=2.13 \mathrm{~s}$

One stick moves outside the cup as a bundle of $1 \mathrm{~s}$, that moves back inside as 1 bundle. This will change the 'normal' form to an 'overload', or to an 
'underload' leading to negative numbers that may be used freely in childhood even if adults abstain from doing so:

$$
\begin{aligned}
& T=7=\mathrm{IIIIIII} \rightarrow \mathrm{HHIIII} \rightarrow \text { [ [ ] IIII } \rightarrow 1 B 43 \mathrm{~s}=1.43 \mathrm{~s} \\
& T=7=\mathrm{I} \mathrm{I} \mathrm{IIIII} \rightarrow \mathrm{HHHHH} \rightarrow[\mathrm{HID}] \mathrm{H} \rightarrow 3 B-23 \mathrm{~s}=3 .-23 \mathrm{~s}
\end{aligned}
$$

\section{Re-Counting in a Different Unit}

Re-counting in a different unit means changing units, also called proportionality. Re-counting $34 \mathrm{~s}$ in $5 \mathrm{~s}$, the re-count formula and a calculator predict the result $25 \mathrm{~s} \& 2$ by entering ' $3 * 4 / 5$ ' and taking away the $25 \mathrm{~s}$.

$$
\begin{array}{|lr|}
\hline \mathbf{3} * \mathbf{4} / \mathbf{5} & \text { 2.some } \\
\mathbf{3} * \mathbf{4}-\mathbf{2} * \mathbf{5} & 2 \\
\hline
\end{array}
$$

Figure 6. A calculator predicts how 34 s re-counts in $5 \mathrm{~s}$ as $2.25 \mathrm{~s}$.

\section{Re-Counting from Icons to Tens}

A calculator has no ten-button. Instead, to re-count an icon-number as 3 $4 \mathrm{~s}$ in tens, it gives the result 1.2 tens directly in a short form that leaves out the unit and misplaces the decimal point one place to the right, strangely enough called a 'natural' number.

$$
3 * 4
$$

Figure 7. A calculator predicts how 34 s re-counts in tens as 1.2 tens.

Re-counting from icons to tens, $34 \mathrm{~s}$ is a geometrical block that increases its base. Therefore, it must decrease its height to keep the total unchanged.

Re-counting in tens is called multiplication tables to be learned by heart. However, the ten-by-ten table can be reduced to a 4-by-4 table since 5 is half of ten and 6 is ten less 4 , and 7 is ten less 3 etc. Thus $T=4 * 7=47$ s that re-counts in bundles of tens as

$$
T=4 * 7=4 * 1 B-3 \text { tens }=4 B-12 \text { tens }=3 B-2 \text { tens }=2 B 8 \text { tens }=28
$$

Such results generalize to algebraic formulas as $a^{*}(b-c)=a^{*} b-a^{*} c$.

\section{Re-Counting from Tens to Icons}

Re-counting from tens to icons will decrease the base and increase the height. The question ' 38 is ? $7 \mathrm{~s}$ ' is called an equation ' $38=u^{*} 7$ ', using the letter $u$ for the unknown number. An equation is easily solved by recounting 38 in $7 \mathrm{~s}$, thus providing a natural 'to opposite side with opposite sign' method as a difference to the traditional 'do the same to both sides' method.

\begin{tabular}{|lll|}
\hline$* 7=38=(38 / 7) * 7$ & so & $u=38 / 7=53 / 7$
\end{tabular}

Figure 8. An equation solved by re-counting, the OppositeSide\&Sign method. 


\section{Once Counted, Totals Can be Added On-Top or Next-To}

To add on-top by asking ' $35 \mathrm{~s}$ and $23 \mathrm{~s}$ total how many 5s?', the units must be the same. So, $23 \mathrm{~s}$ must be re-counted in $5 \mathrm{~s}$ as $1 B 15 \mathrm{~s}$ that added to the $35 \mathrm{~s}$ gives $4 B 15 \mathrm{~s}$.

Using a calculator to predict the result, we use a bracket before counting in 5 s: Asking ' $(3 * 5+2 * 3) / 5$ ', the answer is ' 4 . Some'. Taking away 45 s leaves 1. So again, we get the result $4 B 15 \mathrm{~s}$.

$$
\begin{array}{|lr|}
\hline(3 * \mathbf{5}+\mathbf{2} * \mathbf{3}) / \mathbf{5} & \text { 4.some } \\
(\mathbf{3} * \mathbf{5}+\mathbf{2} * \mathbf{3})-\mathbf{4} * \mathbf{5} & 1 \\
\hline
\end{array}
$$

Figure 9. A calculator predicts how 35 s and $23 \mathrm{~s}$ re-counts in $5 \mathrm{~s}$ as $4.15 \mathrm{~s}$.

To add next-to by asking ' 3 5s and 23 s total how many 8 s?', we add by areas, called integral calculus. With blocks we get the answer $2 B 58 \mathrm{~s}$.

Using a calculator to predict the result, we use a bracket before counting in 8 s: Asking ' $(3 * 5+2 * 3) / 8$ ', the answer is ' 2 . Some'. Taking away 28 s leaves 5 . So again, we get the result $2 B 58 \mathrm{~s}$.

\begin{tabular}{|lr|}
\hline$(3 * 5+2 * 3) / 8$ & $2 . s o m e$ \\
$(4 * 5+2 * 3)-2 * 8$ & 5 \\
\hline
\end{tabular}

Figure 10. A calculator predicts how $35 \mathrm{~s}$ and $23 \mathrm{~s}$ re-counts in 8 s as 2.58 s.

\section{Reversing Adding On-Top and Next-To}

Reversed addition may be called backward calculation or solving equations. Reversing next-to addition may be called reversed integration or differentiation. Asking ' 35 s and how many 3 s total $2 B 6$ 8s?', using blocks gives the answer $2 B 13 \mathrm{~s}$.

Using a calculator to predict the result, the remaining is bracketed before counting in $3 \mathrm{~s}$.

$$
\begin{array}{|lr|}
\hline(2 * 8+6-3 * 5) / 3 & 2 \\
(2 * 8+6-3 * 5)-2 * 3 & 1 \\
\hline
\end{array}
$$

Figure 11. A calculator predicts how 2.68 s re-counts in $35 \mathrm{~s}$ and $2.13 \mathrm{~s}$.

Adding or integrating two areas next-to each other means multiplying before adding. Reversed integration, i.e. differentiation, then means subtracting before dividing, as shown by the gradient formula $y^{\prime}=\Delta y / t=(y 2-y 1) / t$.

\section{Double-Counting in Two Units Creates Per-Numbers and Proportionality}

Double-counting the same total in two units is called proportionality, which produces 'per-numbers' as e.g. $2 \$$ per $5 \mathrm{~kg}$, or $2 \$ / 5 \mathrm{~kg}$, or $2 / 5 \$ / \mathrm{kg}$.

To answer the question ' $T=6 \$=? \mathrm{~kg}$ ' we use the per-number to re-count 6 in $2 \mathrm{~s}$, that many times we have $5 \mathrm{~kg}: T=6 \$=(6 / 2) * 2 \$=(6 / 2) * 5 \mathrm{~kg}=$ 
$3 * 5 \mathrm{~kg}=15 \mathrm{~kg}$. And vice versa: Asking ' $T=20 \mathrm{~kg}=? \$$ ', the answer is $T=20 \mathrm{~kg}$ $=(20 / 5) * 5 \mathrm{~kg}=(20 / 5) * 2 \$=4 * 2 \$=8 \$$.

A total can be double-counted in colored blocks of different values, e.g. 1 red per 3 blues. Here, a total of 10 blues re-counts as $T=7 b \& 1 r=4 b \& 2 r=$ $1 b \& 3 r$. Likewise, a total of 3 reds re-counts as $T=3 b \& 2 r=6 b \& 1 r=9 b$. Placed next to each other, this introduces a primitive coordinate system.
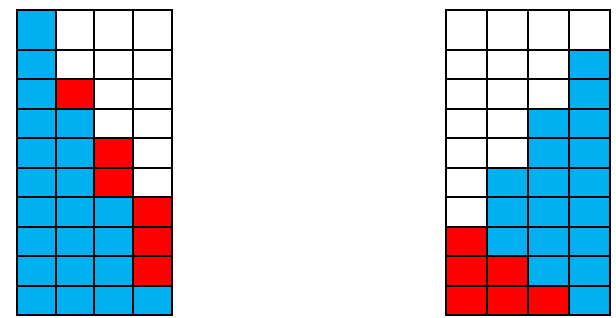

Figure 12. 10 blues left, and 3 reds right, re-counted in combinations.

\section{Double-Counting in the Same Unit Creates Fractions as Per-Numbers}

Double-counting a total in the same unit, per-numbers take the form of fractions, e.g. as $3 \$$ per $5 \$=3 / 5$; or percentages as $3 \$$ per $100 \$=3 / 100=3 \%$.

Thus, to find $3 \$$ per $5 \$$ of $20 \$$, or $3 / 5$ of 20 , we re-count 20 in $5 \mathrm{~s}$ as $20=$ $(20 / 5) * 5=4 * 5$. Now we have two options. Seeing 20 as $45 \mathrm{~s}, 4$ times we get 3 , i.e. $4 * 3=12$; and seeing 20 as 54 s, we get 34 s, i.e. $3 * 4=12$.

Likewise, to find what $3 \$$ per $5 \$$ is in percent, i.e. per 100 , we re-count 100 in $5 \mathrm{~s}$ as $100=(100 / 5) * 5=20 * 5$. Again, we have two options. Seeing 100 as 205 s, 20 times we get 3 , i.e. $20 * 3=60$; and seeing 100 as 520 s, we get 3 20 s, i.e. $3 * 20=60$. So, 3 per 5 gives 60 per 100 or $60 \%$.

Including or removing units will enlarge or reduce fractions:

$4 / 6=43 \mathrm{~s} / 63 \mathrm{~s}=4 * 3 / 6 * 3=12 / 18$

$4 / 6=2 * 2 / 3 * 2=22 \mathrm{~s} / 32 \mathrm{~s}=2 / 3$

\section{Adding Per-numbers Roots Integral Calculus before Differential Calculus}

Adding $2 \mathrm{~kg}$ at $3 \$ / \mathrm{kg}$ and $4 \mathrm{~kg}$ at $5 \$ / \mathrm{kg}$, the 'unit-numbers' 2 and 4 add directly, but the per-numbers 3 and 5 must be multiplied first, thus creating areas. So per-numbers and fractions are not numbers, but operators needing numbers to become numbers. Per-numbers thus add by the areas under the per-number graph, here being 'piecewise constant'.

Asking ' 3 seconds at $4 \mathrm{~m} / \mathrm{s}$ increasing steadily to $5 \mathrm{~m} / \mathrm{s}$ ', the per-number is 'locally constant'. This concept is formalized by an 'epsilon-delta criterion' seeing three forms of constancy: $y$ is 'globally constant' $c$ if, for any positive number epsilon, the difference between $y$ and $c$ is less than epsilon. And $y$ is 'piecewise constant' $c$ if an interval-width delta exists such that, for any positive number epsilon, the difference between $y$ and $c$ is less than epsilon in this interval. Interchanging epsilon and delta makes $y$ 'locally constant' or 
continuous. Likewise, the change ratio $\Delta y / \Delta x$ can be globally, piecewise or locally constant, in the latter case written as $d y / d x=y$ '.

With locally constant per-numbers, the area under the graph splits up into countless strips that add easily if written as differences since the middle terms then will disappear, leaving just the difference between the end- and start-values. Thus, adding areas precedes and motivates differential calculus.

\section{Using Letters and Functions for Unspecified Numbers and Calculations}

At the language level we can set up a calculation with an unspecified number $u$, e.g. $T=2+?=2+u$. Also, at the meta-language level we can set up an unspecified formula with an unspecified number $u$, written as $T=f(u)$.

With one unspecified number, a formula becomes an equation as $8=$ $2 * u$; with two, a formula becomes a function as $\mathrm{T}=2 * u$; and with three, a formula becomes a surface as $\mathrm{T}=2 * u+2 * w$.

Although we can write it, $T=f(2)$ is meaningless since 2 is not an unspecified number. When specified, a function can be linear or exponential, but it cannot be a number or increase. A total can increase, but the way it does so cannot. Mixing language and meta-language creates meaningless sentences as 'the predicate ate the apple'.

A general number-formula as e.g. $T=a^{*} x^{\wedge} 2+b^{*} x+c$ is called a polynomial. It shows the four different ways to unite, called algebra in Arabic: addition, multiplication, repeated multiplication or power, and block-addition or integration. Which is precisely the core of traditional mathematics education, teaching addition and multiplication together with their reverse operations subtraction and division in primary school; and power and integration together with their reverse operations factor-finding (root), factor-counting (logarithm) and per-number-finding (differentiation) in secondary school.

Including the units, we see there can be only four ways to unite numbers: addition and multiplication unite changing and constant unit-numbers, and integration and power unite changing and constant per-numbers. We might call this beautiful simplicity 'the algebra square'.

\begin{tabular}{|l|l|c|}
\hline Operations unite/ & Changing & Constant \\
split Totals in & $\boldsymbol{T}=\boldsymbol{a}+\boldsymbol{n}$ & $\boldsymbol{T}=\boldsymbol{a}^{*} \boldsymbol{n}$ \\
\hline Unit-numbers & $\boldsymbol{T}-n=a$ & $T / n=a$ \\
$\mathrm{~m}, \mathrm{~s}, \mathrm{~kg}, \$$ & $\boldsymbol{T}=\int \boldsymbol{a} * \boldsymbol{d}$ & $\boldsymbol{T}=\boldsymbol{a}^{\wedge} \boldsymbol{n}$ \\
\hline Per-numbers & $d T / d n=a$ & $n \sqrt{ } T=a \quad \log _{a} \boldsymbol{T}=n$ \\
$\mathrm{~m} / \mathrm{s}, \$ / \mathrm{kg}, \$ / 100 \$=\%$ &
\end{tabular}

Figure 13. The 'algebra-square' shows the four ways to unite or split numbers. 
The number-formula contains the formulas for constant change:

$T=b^{*} x$ (proportional)

$T=b^{*} x+c$ (linear)

$T=a * x^{\wedge} n$ (elastic)

$T=a * n^{\wedge} x$ (exponential)

$T=a^{*} x^{\wedge} 2+b^{*} x+c$ (accelerated)

If not constant, numbers change: constant change roots pre-calculus, predictable change roots calculus, and unpredictable change roots statistics using confidence intervals to 'post-dict' what we cannot 'pre-dict'.

Combining linear and exponential change by $n$ times depositing $a \$$ to an interest rate $r \%$, we get a saving $A \$$ predicted by a simple formula, $A / a=R / r$, where the total interest rate $R$ is predicted by the formula $1+R=(1+r)^{\wedge} n$.

The formula and the proof are both elegant: in a bank, an account contains the amount $a / r$. A second account receives the interest amount from the first account, $r^{*} a / r=a$, and its own interest amount, thus containing a saving $A$ that is the total interest amount $R * a / r$, which gives $A / a=R / r$.

\section{Trigonometry before Geometry}

The tradition introduces plane geometry before coordinate geometry and trigonometry. A difference is the opposite order with trigonometry first since halving a block by its diagonal allows the base and the height to be re-counted in the diagonal or in each other to create the per-numbers sine, cosine, tangent and gradient:

height $=($ height $/$ base $) *$ base $=$ tangent $*$ base $=$ gradient $*$ base .

This allows a calculator to find $p i$ from a formula: $\pi=n * \tan (180 / n)$ for $n$ sufficiently large; and it allows to predict an angle $A$ form its base $b$ and height $a$ by reversing the formula $\tan A=a / b$.

Integrating plane and coordinate geometry allows geometry and algebra to always go hand in hand. In this way solving algebraic equations predicts intersection points in geometrical constructions, and vice versa.

\section{Testing a Many-matics Micro-curriculum}

A ' 1 cup and 5 sticks' micro-curriculum can be designed to help a class stuck in division. The intervention begins by bundle-counting 5 sticks in $2 \mathrm{~s}$, using the cup for the bundles. The results, $1 B 32 \mathrm{~s}$ and $2 B 12 \mathrm{~s}$ and $3 B-12 \mathrm{~s}$, show that a total can be counted as an inside number of bundles, and an outside number of singles; and written in three ways: overload and normal and underload.

So, to divide 336 by 7 , we move 5 bundles outside as 50 singles to re-count 336 with an overload: $336=33 B 6=28 B 56$, which divided by 7 gives $4 B 8=48$. With multiplication, singles move inside as bundles: $7 * 4 B 8=28 B 56$ $=33 B 6=336$. 'Is it that easy?' is a typical reaction. 


\section{Algebra before Arithmetic may now be Possible}

Introducing algebra before arithmetic was central to the New Math idea and to the work of Davidov (Schmittau, 2004). Introducing algebra as generalized arithmetic, the book 'Early Algebra' describes how 'a fourth-grade USA class is investigating what happens to the product of a multiplication expression when one factor is increased by a certain amount.' (Kieran et al, 2016, p.17). The investigation begins with an example showing that $7 * 3=21$, and $7 * 5=35$, and $9 * 3=27$.

In a first-grade class working with block-numbers with the bundle as the unit, the answer would be: $7 * 3$ is $73 \mathrm{~s}$, and $7 * 5$ is $75 \mathrm{~s}$, and $9 * 3$ is $93 \mathrm{~s}$. So $7 * 5$ means that $72 \mathrm{~s}$ is added next-to $73 \mathrm{~s}$. Re-counted in tens this will increase the $2 B 1$ tens with $1 B 4$ tens to $3 B 5$ tens. Likewise, $9 * 3$ means that $23 \mathrm{~s}$ is added on-top of $73 \mathrm{~s}$. Re-counted in tens this will increase the $2 B 1$ tens with $0 B 6$ tens to $2 B 7$ tens.

Adding 2 to both numbers means adding additional 22 s. Re-counted in tens this will increase the $2 B 1$ tens with $1 B 4$ tens and $0 B 6$ tens and additional $0 B 4$ tens to $4 B 5$ tens.

Counting 7 as 9 less 2 , and 3 as 5 less 2 , will decrease the $95 \mathrm{~s}$ with $25 \mathrm{~s}$ and $29 \mathrm{~s}$. Only now we must add the $22 \mathrm{~s}$ that was removed twice, so $(9-2) *(5-2)=9 * 5-9 * 2-2 * 5+2 * 2$ as shown on a western ten by ten abacus as a 9 by 5 block. This roots the algebraic formula $(a-b)^{*}(c-d)=a^{*} c-a^{*} d-$ $b^{*} c+b * d$.

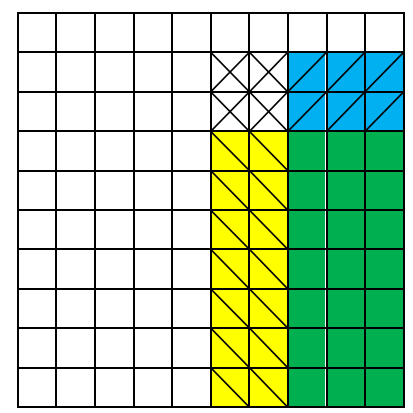

Figure 14. An abacus shows that $7 * 3=(9-2) *(5-2)=9 * 5-9 * 2-2 * 5+2 * 2$.

Later follows a discussion on solving equations (pp. 25-29). In a first-grade class working with block-numbers with the bundle as the unit, solving the equation $3 x+9=5 x+1$, the geometrical answer would be: to the left we have a block of $3 B 9 x \mathrm{~s}$, and to the right we have a block of $5 B 1 x \mathrm{~s}$. Removing 3 bundles and 1 single from both, we get $8=2 x$. Re-counting 8 in $2 \mathrm{~s}$ we get $2 * x=8=(8 / 2) * 2$, so $x=8 / 2=4$.

The algebraic answer would be similar: to the left we have 3 bundles inside and 9 singles outside the bundle-cup, and to the right we have 5 bundles inside and 1 single outside. Removing 3 bundles from the inside and 1 single 
from the outside, we get $8=2 x$. Re-counting 8 in 2 s we get $2 * x=8=(8 / 2) * 2$, so $x=8 / 2=4$.

Using block-numbers instead of line-numbers thus allows introducing algebra before arithmetic since with the re-count formula, counting and re-counting and double-counting precede addition.

\section{Conclusion and Recommendation}

Among the many research articles on counting and arithmetic, only few deal with block-numbers (Zybartas and Tarp, 2005). Dienes (2002), the inventor of Multi-base blocks, has similar ideas when saying (p. 1):

The position of the written digits in a written number tells us whether they are counting singles or tens or hundreds or higher powers. (..) My contention has been, that in order to fully understand how the system works, we have to understand the concept of power. (..) In school, when young children learn how to write numbers, they use the base ten exclusively and they only use the exponents zero and one (namely denoting units and tens), since for some time they do not go beyond two digit numbers. So neither the base nor the exponent are varied, and it is a small wonder that children have trouble in understanding the place value convention.

Instead of talking about bases and higher powers, working with icon-bundles and bundles of bundles will avoid that "neither the base nor the exponent are varied'. By seeing bundles as existence and bases as essence, block-numbers differ from Dienes' multi-base blocks that seem to have set-based mathematics as the goal, and blocks as a means.

Set, however, changed mathematics from a bottom-up Greek 'Many-matics' into today's self-referring top-down 'meta-matism', a mixture of 'meta-matics' with concepts defined top-down instead of bottom-up, and 'mathe-matism' with statements true inside but seldom outside classrooms where adding numbers without units as ' $2+3$ IS 5 ' meets counter-examples as 2 weeks +3 days is 17 days; in contrast to ' $2 * 3=6$ ' stating that 23 s can always be re-counted as $61 \mathrm{~s}$.

So, mathematics is not hard by nature but by choice. And yes, a different way exists to its outside goal, mastery of Many. Still, it teaches line-numbers as essence to be added without units and without being first bundle-counted and re-counted and double-counted. By neglecting the existence of block-numbers and re-counting, it misses the golden learning opportunities from introducing formulas, proportionality, calculus and equations in early childhood education through its grounded alternative, Many-matics.

Consequently, let us welcome 'good' 2-dimensional block-numbers and drop 'bad' 1-dimensional line-numbers and 'evil' fractions (Tarp, 2018b). Let us bundle-count and re-count and double-count before adding on-top and 
next-to. Let us use full sentences about how to count and (re)unite totals. And, let difference-research use sociological imagination to design a diversity of micro-curricula (Tarp, 2017) to test if Many-matics makes a difference by fulfilling the 'Mathematics for All' dream. things.

Let existence precede essence in mathematics education also. So, think

\section{References}

Arendt, H. (1963). Eichmann in Jerusalem, a report on the banality of evil.

London: Penguin Books.

Bauman, Z. (1990). Thinking sociologically. Oxford, UK: Blackwell.

Bauman, Z. (1992). Intimations of postmodernity. London, UK: Routledge.

Dienes, Z. (2002). What is a base? Retrieved from

www.zoltandienes.com/academic-articles.

Foucault, M. (1995). Discipline \& punish. New York: Vintage Books.

Freudenthal, H. (1973). Mathematics as an educational task.

Dordrecht-Holland: D. Reidel Publishing Company.

Glaser B. G. \& Strauss A. L. (1967). The discovery of grounded theory. New York: Aldine de Gruyter.

Heidegger, M. (1962). Being and time. Oxford, UK: Blackwell.

Kieran, C., Pang J. S., Schifter, D. \& Ng, S. F. (2016). Early algebra: research into its nature, its learning, its teaching (ICME 13 topical surveys). Hamburg: Springer Open.

Kuhn T.S. (1962). The structure of scientific revolutions. Chicago: University of Chicago Press.

Lyotard, J. (1984). The postmodern condition: a report on knowledge. Manchester, UK: Manchester University Press.

Marino, G. (2004). Basic writings of existentialism. New York: Modern Library.

Mills, C. W. (1959). The sociological imagination. UK: Oxford University Press.

Piaget, J. (1970). Science of education of the psychology of the child. New York: Viking Compass.

Russell B. (1945). A history of western philosophy. New York: A Touchstone Book.

Schmittau, J. \& Morris, A. (2004). The development of algebra in the elementary mathematics curriculum of V.V. Davydov. The Mathematics Educator, 8 (1), 60-87.

Tarp, A. (2016). From essence to existence in mathematics education. Philosophy of Mathematics Education Journal, 31.

Tarp, A. (2017). Math Ed \& Research 2017. Retrieved 4.4.2018 from http://mathecademy.net/2017-math-articles/. 
Tarp, A. (2018a). A Heidegger view on how to improve mathematics education. Philosophy of Mathematics Education Journal, 33.

Tarp, A. (2018b). Good, bad \& evil mathematics - tales of totals, numbers \& fractions. Flexibility in Mathematics Education: Proceedings of the 8th ICMI-East Asia Regional Conference on Mathematics Education, Taipei, Taiwan, May 7-11, 2018. Forthcoming.

The Organisation for Economic Co-operation and Development (OECD). (2015). Improving schools in Sweden: an OECD perspective.

Retrieved from http:// www.oecd.org/edu/school/ improving-schoolsin-sweden-an-oecd-perspective.htm.

Zybartas, S. \& Tarp, A. (2005). One digit mathematics. Pedagogika (78/2005). Vilnius, Lithuania.

\section{Author:}

Allan Tarp

The MATHeCADEMY.net, Denmark

Email: Allan.Tarp@MATHeCADEMY.net 